\title{
Thermophysical measurements on transition-metal tungstates \\ I. Heat capacity of zinc tungstate from 5 to $550 \mathrm{~K}^{a}$
}

\author{
CHRISTOPHER P. LANDEE and EDGAR F. WESTRUM, JR. ${ }^{b}$
}

Department of Chemistry, The University of Michigan, Ann Arbor, Michigan 48104, U.S.A.

(Received 7 April 1975)

\begin{abstract}
Redetermination of the heat capacity of $\mathrm{ZnWO}_{4}$ after chemical removal of the $\mathrm{ZnO}$ phase from a previous sample has provided better values for chemical thermodynamic properties. At $298.15 \mathrm{~K} C_{p}, S^{\circ}$, and $-\left\{G^{\circ}(T)-H^{\circ}(0)\right\} / T$ are found to be $27.44,28.51$, and 12.991 $\mathrm{cal}_{\mathrm{th}} \mathrm{K}^{-1} \mathrm{~mol}^{-1}$.
\end{abstract}

\section{Introduction}

Zinc tungstate is isostructural with the $\mathrm{NiWO}_{4}$-type tungstates (e.g. $\mathrm{MnWO}_{4}$ (hübnerite), $\mathrm{FeWO}_{4}$ (ferberite), $\mathrm{CoWO}_{4}$, and $\mathrm{NiWO}_{4}$ ) and, hence, its heat capacity is important as an estimate of the lattice heat-capacity contribution in resolving the magnetic transitions of the other substances. Previously reported heat capacities of zinc tungstates ${ }^{(1,2)}$ are deficient in that a separate zinc oxide phase was ascertained as present by X-ray analysis and subsequent chemical analysis indicated $(3.51 \pm 0.7)$ per cent by mass or 12.3 moles per cent of the oxide. Although adjustment for the presence of the $\mathrm{ZnO}$ was made on the basis of additivity, development of chemical methods for the successful removal of oxide phases from other transition metal tungstates $^{(3)}$ has permitted us to remove the zinc oxide from the sample and measure directly the heat capacity of the now pure zinc tungstate sample. The direct determination of the heat capacity has led to values differing by approximately 1 per cent from those prcviously reported; the chemical analysis is apparently at fault.

\section{Experimental}

The sample described in the previous work ${ }^{(1)}$ was crushed to a fine powder in an agate mortar, washed in dilute $\left(0.2 \mathrm{~mol} \mathrm{dm}{ }^{-3}\right)$ hydrochloric acid, rinsed in distilled water, and dried in an oven. All X-ray lines found were indexed as pertinent to the

a This work has been supported by National Science Foundation contract NSF GP-42525X.

$b$ To whom correspondence concerning this paper should be directed. 
zinc tungstate lattice; no $\mathrm{ZnO}$ lines were detected. The lattice parameters derived for this sample: $a=(0.4692 \pm 0.0001) \mathrm{nm}, b=(0.5719 \pm 0.0002) \mathrm{nm}, c=(0.4927 \pm$ $0.0001) \mathrm{nm}$, and $\beta=(90.61 \pm 0.02)^{\circ}$, are in good accord with those of other investigators. $^{(1)}$ Details of the X-ray powder pattern are given elsewhere. ${ }^{(3)}$ Duplicate analyses for zinc and tungsten ${ }^{(4)}$ indicate 20.42 and 20.67 mass per cent zinc (theor. 20.87) and 57.80 and 57.64 mass per cent of tungsten (theor. 58.70). The mean values correspond to a mole ratio $n(\mathrm{~W}) / n(\mathrm{Zn})$ of $(1.000 \pm 0.004)$ and, hence, unity within the reliability of the determinations. Earlier tests on this sample reveal the difficulty of obtaining complete dissolution of the sample; systematic deviation from the theoretical values is therefore not considered important.

As was done originally, ${ }^{(1)}$ values were determined in calorimeter W-30 in the Mark-II adiabatic cryostat and in W-22-0 in the Mark-IV adiabatic thermostat. All conditions parallel closely those described earlier except that the sample masses were somewhat reduced to about $57.8 \mathrm{~g}$.

\section{Results and discussion}

The experimental heat capacities corrected for curvature have been listed in chronological sequence in table 1 so that the temperature increments can be deduced approximately from the mean temperatures. These results have been taken against the IPTS-48 temperature scale. The molar mass of $\mathrm{ZnWO}_{4}$ was taken as 313.2276 $\mathrm{g} \mathrm{mol}^{-1}$. The precision of these results parallels that in the original presentation. ${ }^{(1)}$

The heat capacity and derived thermodynamic properties presented in table 2 at selected temperatures are similarly defined and were smoothed and/or integrated by digital computer and compared with large-scale graphical plots.

The original heat capacity adjusted for impurity is consistently 1 per cent lower from $100 \mathrm{~K}$ to $350 \mathrm{~K}$ than the results reported herc. Below $100 \mathrm{~K}$ the curves of the heat capacities approach and cross so that the original values are higher than the present values below $40 \mathrm{~K}$. The discrepancy indicates the inadequacy of the original adjustment made for the contribution of the zinc oxide impurity. To explain the lack of accord, we have ascertained the amount of zinc oxide originally present both by leaching it from the original sample and by comparison of the heat capacities involved. For the former, a portion of the original sample was crushed, dried to constant mass, leached with $0.2 \mathrm{~mol} \mathrm{dm}{ }^{-3}$ aqueous $\mathrm{HCl}$, dried to constant mass, and reweighed. After correcting for the solubility of pure $\mathrm{ZnWO}_{4}$ in the acid (determined for these conditions), the mass loss was found to be $(2.1 \pm 0.3)$ per cent. Moreover, the mass per cent of $\mathrm{ZnO}$ which best reproduced the originally observed heat capacity of impure $\mathrm{ZnWO}_{4}{ }^{(1)}$ from the new heat-capacity value for this substance over the range 100 to $300 \mathrm{~K}$-the only range of reliable heat capacities of $\mathrm{ZnO}^{(5)}$ - was found to require the presence of $(2.00 \pm 0.03)$ mass per cent of $\mathrm{ZnO}$ in the original sample. These values are in good accord with each other but are substantially lower than the $(3.5 \pm 0.7)$ mass per cent obtained by interpretation of ultimate commercial analyses in the previous study. ${ }^{(1)}$ 
TABLE 1. Heat capacity of zinc tungstate

$$
\left(\mathrm{cal}_{\mathrm{th}}=4.184 \mathrm{~J}\right)
$$

\begin{tabular}{|c|c|c|c|c|c|c|c|}
\hline$\frac{T}{K}$ & $\frac{C_{p}}{\mathbf{Y}^{-1} \mathrm{~mol}^{-1}}$ & $\frac{T}{Y}$ & $\frac{C_{p}}{K^{-1} \mathrm{~mol}^{-1}}$ & $\frac{T}{K}$ & $\frac{C_{p}}{K^{-1} m^{-1}}$ & $\frac{T}{K}$ & $\frac{C_{p}}{K^{-1}}$ \\
\hline K & $\mathrm{cal}_{\mathrm{th}} \mathrm{K}^{-1} \mathrm{~mol}^{-1}$ & & $\mathrm{cal}_{\text {th }} \mathrm{K}^{-1} \mathrm{~mol}^{-1}$ & & $\mathrm{cal}_{\mathrm{th}} \mathrm{K}^{-1} \mathrm{~mol}^{-1}$ & K c & $\mathrm{cal}_{\mathrm{th}} \mathrm{K}^{-1} \mathrm{~mol}^{-1}$ \\
\hline \multicolumn{8}{|c|}{ In Mark II cryostat } \\
\hline & Series I & 300.50 & 27.56 & 147.95 & 17.21 & 15.08 & 0.186 \\
\hline 140.68 & 16.45 & 310.18 & 27.94 & 158.05 & 18.20 & 16.71 & 0.262 \\
\hline 147.72 & 17.17 & 319.75 & 28.36 & & & 18.63 & 0.369 \\
\hline 158.64 & 18.25 & 329.22 & 28.74 & \multirow{2}{*}{\multicolumn{2}{|c|}{ Series III }} & 20.86 & 0.523 \\
\hline 168.00 & 19.13 & 338.62 & 29.06 & & & 23.24 & 0.724 \\
\hline 178.12 & 20.01 & 346.07 & 29.32 & 5.11 & 0.006 & 25.56 & 0.952 \\
\hline 188.98 & 20.91 & & & 5.70 & 0.008 & 27.90 & 1.203 \\
\hline 199.53 & 21.71 & & & 6.17 & 0.011 & 30.59 & 1.521 \\
\hline 209.79 & 22.45 & \multirow{2}{*}{\multicolumn{2}{|c|}{ Series II }} & 6.64 & 0.024 & 33.72 & 1.923 \\
\hline 219.80 & 23.17 & & & 7.27 & 0.019 & 37.42 & 2.434 \\
\hline 229.60 & 23.80 & 82.24 & 9.181 & 7.97 & 0.025 & 42.32 & 3.132 \\
\hline 239.76 & 24.43 & 89.63 & 10.25 & 8.69 & 0.032 & 47.62 & 3.926 \\
\hline 250.29 & 25.05 & 97.67 & 11.31 & 9.40 & 0.043 & 52.95 & 4.758 \\
\hline 260.64 & 25.63 & 107.39 & 12.56 & 10.25 & 0.064 & 59.00 & 5.638 \\
\hline 270.81 & 26.15 & 117.72 & 13.84 & 11.29 & 0.072 & 65.46 & 6.685 \\
\hline 280.83 & 26.69 & 127.64 & 15.02 & 12.33 & 0.094 & 73.05 & 7.805 \\
\hline 290.73 & 27.08 & 137.70 & 16.12 & 13.58 & 0.123 & 81.08 & 9.004 \\
\hline \multicolumn{8}{|c|}{ In Mark IV thermostat } \\
\hline & Series I & 331.45 & 28.73 & 378.53 & 30.22 & \multicolumn{2}{|r|}{ Series V } \\
\hline 332.82 & 28.82 & 341.45 & 29.09 & 388.53 & 30.56 & 460.63 & 32.49 \\
\hline 342.97 & 29.11 & & & & & 470.74 & 32.72 \\
\hline 353.04 & 29.47 & & & & & 480.80 & 32.90 \\
\hline 363.03 & 29.81 & & Series III & & Series IV & 490.80 & 33.17 \\
\hline 372.95 & 30.22 & 298.83 & 27.41 & 392.24 & 30.69 & 500.75 & 33.38 \\
\hline \multirow{4}{*}{382.80} & \multirow[t]{3}{*}{30.37} & 308.82 & 27.84 & 402.15 & 30.96 & & \\
\hline & & 318.70 & 28.22 & 411.99 & 31.27 & \multicolumn{2}{|r|}{ Series VI } \\
\hline & & 328.69 & 28.56 & 421.92 & 31.63 & 502.46 & 33.28 \\
\hline & Series II & 338.79 & 28.90 & 431.95 & 31.89 & 515.64 & 33.47 \\
\hline 330.87 & 27.56 & 348.81 & 29.26 & 441.92 & 32.18 & 525.68 & 33.72 \\
\hline 311.17 & 27.94 & 358.74 & 29.56 & 451.97 & 32.43 & 535.86 & 33.75 \\
\hline 321.35 & 28.39 & 368.60 & 29.94 & 462.11 & 32.62 & 546.00 & 33.79 \\
\hline
\end{tabular}


TABLE 2. Thermodynamic properties of $\mathrm{ZnWO}_{4}$ $\left(\mathrm{cal}_{\text {th }}=4.184 \mathrm{~J}\right)$

\begin{tabular}{rcccc}
\hline$\frac{T}{\mathrm{~K}}$ & $C_{p}$ & $\left\{S^{\circ}(T)-S^{\circ}(0)\right\}$ & $\frac{\left\{H^{\circ}(T)-H^{\circ}(0)\right\}}{\mathrm{cal}_{\mathrm{th}} \mathrm{mol}^{-1}}$ & $\frac{-\left\{G^{\circ}(T)-H^{\circ}(0)\right\} / T}{\mathrm{cal}_{\mathrm{th}} \mathrm{K}^{-1} \mathrm{~mol}^{-1}}$ \\
\hline 5 & 0.006 & 0.002 & 0.008 & 0.001 \\
10 & 0.049 & 0.017 & 0.125 & 0.004 \\
25 & 0.893 & 0.290 & 5.511 & 0.070 \\
50 & 4.294 & 1.880 & 67.73 & 0.525 \\
100 & 11.619 & 7.169 & 470.52 & 2.464 \\
& & & & \\
150 & 17.41 & 13.026 & 1202.5 & 5.009 \\
200 & 21.75 & 18.66 & 2187.1 & 7.725 \\
250 & 25.03 & 23.88 & 3360.1 & 10.442 \\
300 & 27.52 & 28.68 & 4676.9 & 13.087 \\
350 & 29.36 & 33.06 & 6101 & 15.63 \\
400 & 30.94 & 37.09 & 7609 & 18.07 \\
450 & 32.32 & 40.82 & 9192 & 20.39 \\
500 & 33.29 & 44.27 & 10834 & 22.61 \\
550 & 33.85 & 47.48 & 12514 & 24.72 \\
273.15 & 26.28 & 26.15 & 3954.2 & 11.678 \\
298.15 & 27.44 & 28.51 & 4626.1 & 12.991 \\
\hline
\end{tabular}

We consider that the possibility that 1.5 per cent by mass of $\mathrm{ZnO}$ could still remain in the pure sample is excluded by the following facts. (1) The present mole ratio $n(\mathrm{Zn}) / n(\mathrm{~W})$ is $(1.00 \pm 0.004)$; whereas a 1.5 mass per cent of $\mathrm{ZnO}$ contamination would yield a mole ratio of 1.059 . (2) The Guinier X-ray technique is capable of detecting impurity phases of less than 0.5 mass per cent, one third of the level required to account for the discrepancy, but no zinc oxide lines are observed from the pure sample.

\section{REFERENCES}

1. Lyon, W. G.; Westrum, E. F., Jr. J. Chem. Thermodynamics 1974, 6, 763.

2. Lyon, W. G.; Westrum, E. F., Jr. J. Chem. Thermodynamics 1974, 6, 781.

3. Landee, C. P. Doctoral thesis submitted to the University of Michigan, Ann Arbor, Michigan. 1975.

4. The analyses were performed by the Schwarzkopf Microanalytical Laboratory, 56-19 37th Avenue, Woodside, New York 11377. They report that the sample was decomposed in an acid mixture and then the zinc determined by atomic absorption. The tungsten was determined colorimetrically according to the method of Gottschalk (Anal. Chem. 1962, 4173).

5. Maier, C. G.; Parks, G. S.; Anderson, C. T. J. Amer. Chem. Soc. 1926, 48, 2564. Millar, R. W. J. Amer. Chem. Soc. 1928, 50, 2653. Clusius, K.; Harteck, P. Z. Phys. Chem. 1928, 134, 243. 